\title{
A IMPORTÂNCIA DA CULTURA ORGANIZACIONAL E O SEU REFLEXO NA COMUNICAÇÃO INTERNA
}

\author{
Samila Silva VARJÃO ${ }^{1}$ \\ Antônio Carlos ESTENDER ${ }^{2}$ \\ ${ }^{1}$ Graduada em Administração pela Universidade Guarulhos. samila_vajao@ hotmail.com \\ ${ }^{2}$ Mestre em Administração, professor na Universidade Guarulhos. estender@uol.com.br
}

Recebido em: 24/11/2015 - Aprovado em: 13/07/2016 - Disponibilizado em: 18/12/2016

\begin{abstract}
RESUMO:
A presente pesquisa visa apresentar uma análise sobre a importância da cultura organizacional e sua repercussão sobre o comportamento organizacional. Compreender a gestão de pessoas adotada por uma empresa do ramo de Construção Civil, levando em consideração a influência e o reflexo na comunicação interna em seu sucesso. Nesse sentido ressalta a importância da necessidade da comunicação entre o departamento organizacional. O método científico para elaboração deste artigo seguiu os passos da revisão de literatura e incluiu: identificação do tema, levantamento bibliográfico, seleção de texto, estruturação preliminar do estudo de sua avaliação, interpretação dos resultados e síntese do conhecimento obtido. Por meio da observação foi possível identificar que a comunicação interna não esta sendo obtida de forma coerente existe uma falta de relação interpessoal entre os colaboradores. Os resultados revelam que ainda é um desafio o desenvolvimento de uma gestão estratégica eficiente para mudar a cultura organizacional nesse contexto. Conclui-se que a comunicação interna bem administrada oferece ao grupo a oportunidade de incorporar a sua cultura novos hábitos, entre os seus colaboradores internos no que se refere à busca e transmissão de comunicação
\end{abstract}

Palavras chave: Cultura Organizacional, Comunicação Interna, Comportamento Organizacional, Gestão de Pessoas.

\section{THE IMPORTANCE OF ORGANIZATIONAL CULTURE AND ITS REFLECTION IN THE INTERNAL COMMUNICATION}

\begin{abstract}
:
This research aims to present an analysis of the importance of organizational culture and its impact on organizational behavior. Understand people management adopted by a company in the Construction sector, taking into account the influence and reflection in internal communications in their success. Accordingly emphasizes the importance of the need for communication between the organizational departments. The scientific method for the preparation of this article followed in the footsteps of the literature review and included: issue identification, literature, text selection, preliminary structuring of the study review, and interpretation of results and synthesis of knowledge gained. Through observation were identified that internal communication is not being achieved consistently there is a lack of interpersonal relationships among employees. The results reveal that it is still a challenge to develop an efficient strategic management to change the organizational culture in this context. It is concluded that the well-administered group internal communication offers the opportunity to incorporate a new habits culture, between its internal reviewers with regard to the search and transmission media.
\end{abstract}

Keywords: Culture Organizacional, Comunicação Interna, Comportamento Organizacional, Gestão the Pessoas. 


\section{Introdução}

Diversos trabalhos vêm analisando o tema conforme apontado no referencial teórico em seus diferentes níveis de entendimento e aplicação ao contexto organizacional. Pode-se encontrar na literatura definições para Cultura organizacional e Comunicação interna, o que demanda a construção de um modelo teórico que explicite como esses diferentes conceitos se articula e pode contribuir para o entendimento de propostas de desenvolvimento organizacional.

Este estudo de caso nasceu da presunção que a cultura organizacional constitui elemento essencial para a construção de um universo simbólico que, associado às políticas de administração de recursos humanos, contribui para aproximar e integrar os colaboradores aos princípios e objetivos centrais da organização. Também designa que é pela ótica da comunicação que podemos conhecer e compreender a cultura organizacional, além de captar a lógica das relações internas suas contradições, para melhor compreender os estágios administrativos, os sucessos e fracassos organizacionais e as facilidades ou dificuldades impostas às mudanças organizacionais.

A comunicação envolve a transferência de significado de uma pessoa para outra. Assim, se não houver nenhuma transmissão de informação ou idéias, a comunicação não aconteceu. Se ninguém ouviu o que você disse ou leu o que escreveu, você não se comunicou. Além disso, para a comunicação ter êxito, o significado deve ser entendido. Segundo (FIGUEREDO, 2001), a gestão se deparou com o desafio de criar um sistema de comunicação eficaz, buscando ciência de suas fraquezas e vantagens. Portanto, a comunicação, a transparência de significado, envolve um emissor, que transmite uma mensagem, e também um receptor, que a compreende.

A cultura organizacional como fonte instrumental, tem claras correlações com a comunicação interna. Esta pode ser compreendida enquanto um conjunto de valores e pressupostos básicos, expressos em elementos simbólicos, que em sua capacidade de ordenar, atribuir significações, construir a identidade organizacional, tanto age como elemento de comunicação e consenso como instrumentaliza as relações de dominação (FLEURY, 1991).

$\mathrm{O}$ pensamento de enxergar as organizações como culturas, na qual existe um sistema de convicções compartilhado por todos os membros é um fenômeno relativamente recente. Até meados da década de 1980, as organizações eram 
vistas, quase sempre, apenas como uma forma racional de coordenar e controlar um grupo de pessoas. Possuíam níveis verticais, departamentos, relações de autoridade e assim por diante. Mas as organizações são mais do que isso. Elas têm personalidade própria, assim como as pessoas. Podem ser rígidas ou flexíveis, hostis ou apoiadoras, inovadoras ou conservadoras.

A influência da cultura organizacional é determinante no desenvolvimento da comunicação interna, pois é atraves dela que ocorre a socialização de ideias, se transmite valores e conhecimento. Os autores (NORDVANG; ROLLAND; SIMPSON, 2008a), afirmam que as praticas eficazes de comunicação interna podem afetar positivamente a cultura organizacional e, portanto, contribuir para eficacia global de processos de mudanças e estruturação de uma instituição. A comunicação organizacional funciona como uma ferramenta preciosa dentro das organizações, sendo capaz tanto de condensar tradições como de difundir mudanças. Como afirma (REINALDO, 2009), a cultura organizacional é atualmente analisada como ferramenta para condução de processos de mudança, diagnose ou para solução de problemas na organizações.
Por que a cultura organizacional interfere na comunicação interna? A comunicação interna é um fator estratégico para o sucesso das organizações ela atua principalmente em três frentes: é fundamental para os resultados do negócio, é um fator humanizador das relações de trabalho e consolida a identidade da organização junto aos seus públicos. A comunicação ineficaz dificulta as relações de poder nas organizações trazendo varias conseqüências negativas fazendo transparecer e refletir na cultura organizacional. Com isso, todo o desenvolvimento na organização estará comprometido pela falta de capacidade das pessoas de se comunicarem, se somarem e se tornarem competitivas por meio da visão compartilhada, impedindo, assim, a eficiência e eficácia dos resultados propostos, (CAMPOLINA, 2001).

Analisar a importância da cultura organizacional e da comunicação interna; refletir sobre quais os benefícios traz uma boa cultura organizacional; identificar algumas ferramentas capazes de melhorar o fluxo da comunicação interna, visto que a comunicação é uma ferramenta poderosa para transmitir informações; discutir as possíveis soluções de melhorias encontradas nos departamentos da organização que seja capaz de transparecer uma boa imagem cultural; desenvolver um 
clima favorável entre os colaboradores e uma sensação de pertencimento. Sendo assim, ter uma comunicação interna eficiente é um instrumento de gestão estratégica determinante para garantir a coerência interna e a integração das estratégias do negocio, ou seja, é uma ferramenta poderosa e indispensável para o desenvolvimento do sucesso organizacional. (RUCK; WELCH, 2012). O presente estudo constitui uma contribuição para compreensão dos fatores competitivos da empresa do ramo de Construção Civil pertencente a uma cadeia produtiva do setor Administrativo.

O estudo está estruturado em cinco seções, além desta introdução. Na primeira seção é discutida a questão do referencial teórico; comunicação interna e cultura organizacional. A seguir são detalhados os aspectos metodológicos; pesquisa bibliográfica, pesquisa, Observação direta, entrevista. $\mathrm{Na}$ terceira seção, foi apresentado o setor administrativo da área de Construção Civil. Na quarta seção, as análises e resultados, onde os esforços serão direcionados ao por que a má comunicação interna reflete visivelmente na cultura organizacional. Na última seção, são expostas as conclusões finais.

\section{Referencial Teórico}

\subsection{Cultura Organizacional e}

\section{Comunicação interna}

Para Reinaldo (2009), a cultura organizacional é atualmente analisada como ferramenta para condução de processos de mudança, diagnose ou para solução de problemas nas organizações é a forma de se representar as normas informais e não escritas que orientam o comportamento dos membros de uma organização no dia-a-dia e que direcionam suas ações para o alcance dos objetivos organizacionais. No fundo, é a cultura que define a missão e provoca o nascimento e o estabelecimento dos objetivos da organização.

Na visão de Schein (1985), a cultura organizacional é constituída por três níveis de profundidade conceitua que no primeiro momento a empresa quando constituída necessita de fundadores ou idealizadores a segunda é a diversificação de novos produtos e novos mercados nesse momento a organização pode defrontar-se com subculturas alteração de seus objetivos e mesmo mudança cultural. A fase de maturidade coloca a organização diante de duas opções excludentes: transformação ou morte.

Se as as organizações não possuissem nenhuma cultura dominante e fossem constituidas apenas de diversas 
subculturas, a importância da cultura organizacional seria consideravelmente reduzida, porque não haveria nenhuma interpretação uniforme do que seria um comportamento adequado ou inadequado. É o aspecto de significados comuns da cultura que faz dela um poderoso dispositivo para orientar e modelar o comportamento. Mas não podemos ignorar a realidade de muitas organizações que também possuem subculturas que podem influenciar o comportamento de seus membros.

Para Thevenet (1989), a cultura é um conjunto de hipóteses fundamentais que estruturam a generalidade dos comportamentos da gestão da empresa; é fruto de uma longa experiência, resulta de um longo processo de aprendizagem. Seria, por conseguinte, presunção tentar mudá-la ou imprimir-lhe qualquer outra direção. Não se pode dizer que, para lá dos sinais, dos símbolos, dos comportamentos individuais, há lógicas de ação profundamente enraizadas no subconsciente da empresa e, ao mesmo tempo, promover métodos mais ou menos viáveis de transformação dessa realidade. Já para (PETTIGREW, 1989), afirma categoricamente que é possível, sim, gerenciar a cultura e, em consequência, mudá-la, mas atribui uma grande dificuldade à tarefa. Para ele, é mais fácil ajustar as manifestações da cultura do que mudar o núcleo de crenças e pressupostos básicos da organização.

Segundo Welch (2012), diz que comunicação interna reforça a eficácia organizacional. A comunicação é a maneira de transmitir informações sobre os processos a ser executados de forma organizacional. Entende-se que a comunicação traz bons benefícios para uma organização desde que ela seja transferida de forma adequada em formatos úteis, para que não hajam ruídos e nem sejam interpretadas de forma inadequada, todavia uma boa comunicação traz para o ambiente uma cultura Organizacional diferenciada beneficiando a todos da organização. No mesmo sentido (DIETRICH, 2010), diz que a comunicação está diretamente ligada à capacidade de compartilhar. Portanto a comunicação é um processo de troca de informação entre as pessoas ou entre colaboradores de uma empresa para seu funcionamento de tarefas e divisão de trabalho e todos sejam envolvidos na missão da organização.

A comunicação esta diretamente atrelada a essência da liderança e da gestão empresarial, pois sua aplicabilidade esta vinculada ao relacionamento interpessoal no qual, que mediante o processo comunicativo, os lideres inspiram seus 
colaboradores na prestação de seus serviços organizacionais, além de se comprometerem na conquista dos objetivos e metas almejados e traçados pela empresa. Logo, a comunicação é um instrumento estrategico para o exercicio da liderança.

De acordo com Vargas; Arboleda; Obando, (2009), quando a comunicação é integrada e motivada pode contribuir determinantemente para que o trabalho atinja os objetivos organizacionais com isso podendo definir comunicação interna como o conjunto de ações que a organização coordena com o objetivo de ouvir, informar, mobilizar, educar e manter coesão interna em torno de valores que precisam ser reconhecidos e compartilhados por todos. Segundo ainda (NORDVANG, ROLLAND; SIMPSON 2008b), afirmam que as práticas eficazes de comunicação interna podem afetar positivamente a cultura organizacional alega que a comunicação clara e objetiva traz uma melhor imagem para empresa.

Segundo Santos (2011), a organização da cultura e a comunicação só acontecem a partir da predisposição da informação para as pessoas. Dessa forma, as organizações precisam estar atentas aos processos de gerenciamento estratégico da comunicação interna. A cultura e a comunicação estão ligadas, não dá para pensar nas duas separadamente. A comunicação interna engloaba público interno. O plano de comunicação tem que se preocupar com todos esses segmentos, se não o seu desenvolvimento poderá falhar ou dificultar no meio do caminho.

A comunicação é o espelho da cultura organizacional, pois vai refletir no processo de gerenciar, se as lideranças não tem comunicação eficaz. Como descrito por (Oliveira, Carvalho; Rosa 2012). A cultura organizacional pode ser definida como a personalidade da organização. Portanto a cultura da organização diz respeito de suas praticas, valores, comportamentos, hábitos, políticas. Toda organização cria suas particularidades sua forma de conduzir e direcionar as pessoas envolvidas é a partir da analise da cultura organizacional que os profissionais buscam ferramentas para se comunicar transmitir informações com propósito de atingir os objetivos, porém, não deixando que a má comunicação interfira provocando ruídos e conflitos.

\section{Aspectos Metodológicos}

O método científico para a elaboração deste artigo seguiu os passos da identificação do tema, levantamento bibliográfico, seleção de textos, estruturação preliminar e estruturação lógica do estudo sua avaliação, interpretação dos resultados e síntese do 
conhecimento obtido. Na seleção dos materiais incluídos na revisão, utilizou-se a internet para acessar as bases de dados Spell, Dedalus-Usp, Sibi-Usp, Scientific Eletronic Library Online (Scielo). O critério para identificar os materiais de pesquisa foi que eles contivessem em seus títulos, nas suas palavras chave ou ainda nos seus resumos, as palavras ligadas à temática, tais como: Comunicação Interna e Cultura Organizacional. A busca dos dados foi realizada no período entre 14/02/2015 á 20/06 de 2015.

Os estudos exploratórios provêm informações sobre aspectos específicos dos fenômenos organizacionais, sobre os quais temos pouco conhecimento. São usados quando pouco se sabe sobre as organizações a serem estudadas. Durante a fase exploratória, foi realizada uma revisão teórica com o objetivo de aprofundar os conhecimentos no tema e desenvolver instrumentos de coleta de dados para a segunda fase pela natureza do assunto na literatura e prática na administração foi adotada uma pesquisa descritiva por meio de pesquisa bibliográfica com os objetivos descritos a fim de apresentar de modo mais eficiente o problema, foi também feito o levantamento e tratamento de dados. O método de pesquisa escolhido foi o estudo de caso, por se entender que apresenta melhor aderência ao objetivo e às questões que nortearam o estudo. (TUL; HAWKINS 1976, p. 323) afirmam que "um estudo de caso refere-se a uma análise intensiva de uma situação particular", sobre os fenômenos observados, pois estes são estudados em um ambiente delimitado, controlado, que é específico e não será encontrado em outro lugar. Esta limitação não desaparece mesmo quando são utilizados mais que um caso como ambiente de estudo.

Segundo Rynes e Gephart (2004), um valor importante da pesquisa qualitativa é a recomendação de ações para a resolução do problema proposto e o processo deve vir do pesquisado e não do pesquisador, além de procurar a descrição e compreensão das reais interações humanas, sentidos, e processos que constituem os cenários da vida organizacional na realidade. A pesquisa qualitativa vem ganhando espaço reconhecido nas áreas, de educação e a administração de empresa. A pesquisa qualitativa também parte de questões ou focos de interesses amplos, que vão se definindo a medida que o estudo se desenvolve. Envolve por sua vez a obtenção de dados descritivos sobre pessoas, lugares e processos interativos pelo contato direto do pesquisador com a situação estudada, procurando compreender os fenômenos segundo a 
perspectiva dos participantes da situação em estudo. (GODOY, 2006). Ainda que (MERRIAM, 1998), estudo qualitativo interpretativo pode ser visto como um conjunto de técnicas interpretativas que procuram descrever, decodificar, traduzir e, de alguma forma chegar a um acordo com o significado podem ser encontrados em disciplinas aplicadas em contextos de prática.

A opção pela metodologia qualitativa se faz após a definição do problema e do estabelecimento dos objetivos da pesquisa que se quer realizar. (MANZINI, 2003), salienta que é possível um planejamento da coleta de informações por meio da elaboração de um roteiro com perguntas que atinjam os objetivos pretendidos. O roteiro serviria, então, além de coletar as informações básicas, como um meio para o pesquisador se organizar para o processo de interação com $o$ informante. Os dados são coletados por meio de pesquisa bibliográfica, pesquisa de campo, entrevistas, observações e/ou análise de documentos. (MATTOS, 2010) enfatiza que a entrevista "em profundidade" tem sido cada vez mais utilizada na pesquisa em Administração, considerando a inadequação da metodologia quantitativa à área, uma vez que muitos dos problemas e fenômenos das relações que permeiam as organizações escapam ao pesquisador quando expresso em números e estatísticas. Em conformidade com (FLORES, 1994), os dados qualitativos são elaborados por procedimentos e técnicas tais como a entrevista, a observação direta, o trabalho de campo, a revisão de documentos e trabalham a partir de dados descritivos sobre pessoas, lugares e processos interativos obtidos por meio do contato direto do pesquisador com a situação estudada, procurando compreender os fenômenos segundo a perspectiva dos participantes da situação em estudo, ou seja, dos entrevistados. O trabalho foi desenvolvido por meio de uma pesquisa qualitativa, descritiva, cujos dados foram levantados em fontes bibliográficas, documentais e em entrevistas na cidade de Itaquaquecetuba. Sendo uma pesquisa qualitativa, não existe uma rígida delimitação em relação ao número adequado de sujeitos da entrevista, pois é um dado que pode sofrer alterações no decorrer do estudo, além disso, há a necessidade de complementação de informações, à medida que se tornam redundantes $\mathrm{A}$ entrevista qualitativa pode ser utilizada para provocar a expressão e opinião do entrevistado sobre as questões emanadas do objetivo geral e dos objetivos específicos da pesquisa, buscar as conexões conceituais entre o mundo do 
respondente e o Referencial Teórico, além de Entender a lógica, passo a passo, de uma situação que não está clara (EasterbySmith, 1999).

As entrevistas para esse trabalho foram realizadas de forma individual no local de trabalho, do ramo da Construção Civil Pesada. Para se atingir o propósito desse estudo buscou-se formular um roteiro de entrevista semiestruturada embasada na teoria descrita. Os dados foram analisados em duas etapas: a) análise e compreensão as pesquisas bibliográficas e documentais feitas sobre o tema; b) análise e compreensão das entrevistas realizadas. Segundo (FLICK, 2009). Nas entrevistas semipadronizadas são reconstruídos os conteúdos da teoria subjetiva a partir de questões abertas, perguntas controladas pela teoria e direcionadas para as hipóteses e questões confrontativas. Esse tipo de entrevista caracteriza-se pela introdução de áreas de tópicos e pela formulação intencional de questões baseadas em teorias científicas sobre o tópico, reconstruindo os pontos de vista subjetivos. $\mathrm{Na}$ entrevista centrada no problema combinam-se narrativas com questões que visam focalizar a opinião do entrevistado em relação ao problema em torno do qual a entrevista está centrada. Portanto, o interesse está nos pontos de vistas subjetivos e a pesquisa baseia-se em um modelo do processo com o objetivo de elaborar teorias, com questões voltadas para o conhecimento sobre os fatos ou processo de socialização.

Para Quivy e Campenhoudt (1998). No metodo observação participante é importante ressaltar que implica um alto grau de subjetividade, uma vez que as pessoas se manisfestam de acordo com sua vivencia, historico valores e aspectos culturais. Utiliza-se este tipo de pesquisa quando se quer conseguir informações e conhecimento referente a um determinado problema do qual se busca comprova-lo, ou ainda com a intenção de descobrir novos fenômenos ou relações entre eles. Para a definição dos benefícios decorrentes da implantação de um metodo de comunicação interna eficaz e de uma cultura organizacional, as entrevista Os entrevistados foram seis colaboradores sendo: dois da area administrativos, um de finanças, um de segurança do trabalho, e 2 da área de Recursos Humanos. Um dos propósitos de utilizar as entrevistas como metodo de coleta de dados na pesquisa qualitativa em Administração é explorar os pontos de vista, experiências, crenças e/ou motivações dos indivíduos sobre questões específicas no campo organizacional, atendendo principalmente a finalidades exploratórias, ao abordar experiências e 
pontos de vistas dos atores inseridos nestes contextos.

\section{Miller Fundações (Nome Fictício)}

O estudo em questão foi elaborado a partir de uma empresa no ramo de construção civil, Miller Fundações. Essa empresa possui os setores de departamentos administrativos sem um posicionamento estratégico organizacional, onde não tem uma comunicação eficaz entre os colaboradores. Ela foi fundada em 2007, através de um engenheiro civil uma pessoa boa mais, por ser centralizador não viu que sua empresa cresceu muito e deixou de criar uma missão e visão, que são um dos princípios para se criar uma cultura organizacional, ela foi crescendo e se desenvolvendo sem a capacidade de uma boa administração, a falta de conhecimento do empresário em contratar pessoas qualificadas para desenvolver boas praticas e técnica fez com que hoje a empresa ficasse sem um direcionamento, os colaboradores não tem boas disciplinas e responsabilidades em prestar serviços com dedicação e respeito, quando necessitam de alguma coisa não se pronunciam com os outros departamentos para saber se existe alguma necessidade ou se irão precisar de algo, como as obras ficam distantes uma das outras muitas vezes um setor que precisa de algo da obra e de lá vem um motorista eles não se comunicam para saber se iram precisar de alguma coisa no escritório ou vise versa, simplesmente quando vai vê o motorista já sai e não se comunicou e também no custo que leva um serviço, pois a empresa para executar os serviços necessita de uma colaboração de todos os departamentos desde a contratação até a execução dos serviços prestados.

A empresa tem uma deficiência organizacional que são os reflexos da má administração e da má comunicação tem muitas dificuldades em delegar tarefas e desenvolver atividades com os colaboradores, não consegue fazer um treinamento adequado tudo é feito muito corrido as solicitações para uma integração muitas das vezes não são agendadas no prazo correto e com isso se perde muito tempo, as comunicações não são passadas para os subordinados de forma coerente deixando a ver ruídos, existe pouca interação entre as pessoas fazendo com que isso o trabalho fique improdutivo trazendo muita perca de tempo e custo.

Uma das definições para a cultura organizacional é de (EDGAR SCHEIN, 1984) cultura organizacional é o conjunto de pressupostos básicos que um grupo inventou, descobriu ou desenvolveu ao aprender como lidar com os problemas de adaptação externa e interna e que 
funcionou bem o suficiente para serem considerados validos e ensinados os novos membros como forma correta de perceber, pensar e sentir em relação a esse problema. A cultura organizacional deve embasar a comunicação interna que, por sua vez, deve reforçar os aspectos a serem mantidos e desestimulados os que não condizem com o atual momento da empresa.

Muitas vezes a falta de comunicação gera um conflito entre os colaboradores e $\mathrm{o}$ ambiente fica desagradável. A empresa em estudo enfrenta algumas dificuldades nesse ponto de vista, pois isso deixar transparecer em sua cultura organizacional. É preciso que haja uma forma de comunicação que deixe de ser somente uma provedora de informação, mas para que possa construir uma via de mão dupla, onde se obtenha novos ambiente e relacionamento internos, pois de acordo com (MARCHORI, 2006), as pessoas têm de encontrar um propósito, elas têm que perceber que seu trabalho esta contribuindo para algo que ela valoriza.

O universo de análise dessa investigação corresponde a todos os colaboradores que atuam nas áreas administrativas. Assim, almeja diagnosticar a opiniões de todos os colaboradores e gerentes que atuam com funções de executar ou coordenar serviços administrativos nas áreas de recursos humanos, finanças e segurança do trabalho.

\section{Resultados e Discussão}

Os resultados descritos a seguir foram baseados nas informações colhidas nas entrevistas, também foram colhidas informações no site da organização, as informações retiradas dos sites da empresa contribuíram apenas para complementar a sua descrição. O resultado do estudo tem o objetivo de responder por que a cultura organizacional reflete visivelmente na comunicação interna. Os resultados apresentados buscam traduzir a interpretação do pesquisador, construída a partir da análise das respostas obtidas pelas entrevistas realizadas, bem como, os dados obtidos a partir da observação in loco na organização. As informações foram trabalhadas de forma a apresentar reflexões que venham a contribuir para gestão de pessoas, na expectativa de contribuição para um método eficaz de cultura organizacional e comunicação interna, onde foram identificados muitas conseqüências de falta de comunicação na organização, não existe um sistema de resultados e metas, uma realização de avaliação de feedback deixando ocasionar um índice baixo de produtividade desmotivação, gerando um ambiente de desentendimento e discórdia, falta de 
trabalho em equipe perda de tempo e ganhos financeiros. Por meio das observações foi possível identificar que a empresa precisa de melhorar sua relação interpessoal e também de ferramentas de comunicação interna eficaz partindo da administração geral ou por ser uma empresa de pequeno porte do seu fundador que ele venha possibilitar e abrir oportunidades para novas perspectivas de mudanças.

Quadro 1: Entrevista com os colaboradores dos departamentos existentes na organização

\begin{tabular}{|c|c|}
\hline Departamentos & Citações \\
\hline Administração & $\begin{array}{l}\text { Um dos erros, mais cometida pela } \\
\text { administração é a má comunicação que não é } \\
\text { transmitida adequada, não existe um sistema de } \\
\text { gestão onde são repassados os resultados e as metas } \\
\text { para os funcionários através de reuniões e murais. } \\
\text { Também não existe feedback isso gera } \\
\text { desmotivação, pois ele não tem como expor suas } \\
\text { idéias e sugestões de melhoria, isso tem trazido uma } \\
\text { perda de profissionais por falta de uma interação } \\
\text { interpessoal. Diante dessa situação, o gestor da } \\
\text { empresa deve começar a repensar em forma de } \\
\text { melhorar o sistema de comunicação para que isso } \\
\text { venha ter um impacto positivo melhorando a forma } \\
\text { dos costumes e hábitos. }\end{array}$ \\
\hline Finanças & $\begin{array}{l}\text { Uma má comunicação pode trazer tanto } \\
\text { problema econômico quanto na eficiência da } \\
\text { organização, pode aumentar gastos em recursos } \\
\text { desnecessários, tanto humano como material. A } \\
\text { comunicação interna influencia na tomada de } \\
\text { decisão de diversos setores da organização, perda de } \\
\text { energia no sentido de retrabalho, atrasos nos prazos } \\
\text { de entrega do produto final e perda econômica. Uma } \\
\text { má comunicação pode trazer prejuízos para relação } \\
\text { interpessoais, influencia diretamente no impacto } \\
\text { financeiro das organizações. }\end{array}$ \\
\hline
\end{tabular}




\begin{tabular}{|c|c|}
\hline Recursos Humanos & $\begin{array}{l}\text { Quando a falha na comunicação interna gera } \\
\text { vários transtornos como insegurança, desmotivações } \\
\text { e falta de comprometimento dos colaboradores, } \\
\text { podendo levar a organização ao descrédito ou até } \\
\text { mesmo ao fracasso. A consequiência de uma má } \\
\text { comunicação pode levar a empresa a ter que investir } \\
\text { em treinamentos, palestras reuniões a fim de } \\
\text { abrandarem esse tipo de problemas. E os efeitos da } \\
\text { má comunicação são: falhas de produtividade, perda } \\
\text { de tempo e de ganhos financeiros. Temos falta de } \\
\text { outras ferramentas de comunicação. }\end{array}$ \\
\hline Segurança do Trabalho & $\begin{array}{l}\text { A comunicação interna é a função } \\
\text { responsável pela comunicação efetiva entre } \\
\text { integrantes de uma organização. Onde ela baseia-se } \\
\text { nas teorias e praticas de profissionais bem } \\
\text { relacionados, o que de fato englobam todas as } \\
\text { praticas de processos comunicativos de uma } \\
\text { determinada organização com seu publico interno. } \\
\text { Para que a organização tenha uma comunicação } \\
\text { eficaz e obtenha um padrão de comprometimento o } \\
\text { colaborador precisa saber o quanto ele é importante } \\
\text { dentro da empresa e o quanto a empresa precisa dele } \\
\text { é necessária uma ferramenta que crie padrões. }\end{array}$ \\
\hline
\end{tabular}

Fonte: Elaborado pelo autor.

Analisando os resultados das entrevistas, os profissionais entrevistados apontaram que existe o consenso de que uma das causas principais de insucesso na organização é a falta de feedback, que torna as comunicações deficientes e geradoras de conflitos. De um modo geral, as pessoas não se sentem comprometidas em dar retorno, seja por uma equivocada sensação de poder, falta de hábito, negligência, desvalorização. É possível considerar que há uma insatisfação dos servidores entrevistados em relação aos canais existentes e a falta de interação. A dificuldade de solução para os problemas ligados à comunicação está exatamente na falta de uma educação norteada pela cultura do dialogo, pelo ato de refletir em grupo e pensar com espírito de cada pessoa do grupo, para consolidar um ambiente de convivência das diferenças. Desta maneira todas as consequiências na falha de 
comunicação dentro da empresa são geradas por falta de uma relação interpessoal. (PIMENTA, 2010) explica que através da comunicação interna é possível melhorar o desempenho dos funcionários, desenvolvendo valores tais como: responsabilidade, compromisso, cooperação, solidariedade e dedicação, promovendo pilares fundamentais para o trabalho em equipe.

É preciso que haja um plano de comunicação em fluxo seguencia obedecendo a uma hierarquia para manter níveis dentro da organização; em todas as células de negócio tando desde a administração geral até a produção. também que haja outras ferramentas de comunicação como o extranet que é uma ferramenta onde todos consiga usar os mesmos programas e protocolos de comunicação empregados na internet independente de onde estejam, ter um local de divulgação de informação oficial centralizada como, murais informativos, que haja algum tipo de comunicação e um local sempre adequado para que isso aconteça. Muito importante também é ter uma caixa de sugestões permitindo aos empregados dá suas sugestões e demonstrar suas preocupações, pois é muito importante a empresa ouvir os seus empregados, porque muitas das vezes descobrimos efetivamente os problemas que acontece através dos proprios colaboradores. Deve ser feito através de um procedimento de comunicação interna rotativo reuniões semestrais buscando sempre a melhoria continua e satisfação dos nossos clientes internos no caso os nossos funcionários. (CHIAVENATO, 2005), a eficácia da comunicação pode ser melhorada pela repetição e pela retroalimentação. As duas principais habilidades gerenciais para melhorar a comunicação são: saber ouvir, isto é, captar a mensagem para decodificá-la e interpretá-la adequadamente; e saber transmitir, isto é, falar ou sinalizar a mensagem para que ela seja corretamente interpretada por quem a receba.

É preciso que a organização comece a apostar em ferramentas de comunicação integrada. Dentre essas soluções, que visam à troca alinhada de dados. Por meio da comunicação interna é possível se relacionar com cada um dos membros de sua equipe ou departamentos, motivá-los a agir ao lado da organização, em busca de objetivos comuns. Assim sendo, é importante que as informações sejam únicas e que cada um desses funcionários tenha duvidas e anseios atendidos, a fim de evitar ruídos desnecessários, no entanto, mais importante do que as ferramentas são o planejamento e as pessoas envolvidas no 
desenvolvimento das ações táticas, portanto é importante que todos os departamentos atuem de maneira integrada, para que sejam ressaltados os pontos fortes e trabalhados os pontos fracos deve ser entendida como um sistema de interações em que emissor e receptor interagem e compartilhem seus conhecimentos.

\section{Considerações Finais}

Cultura organizacional e comunicação interna fazem parte do desafio da gestão da organização. O início desse trabalho teve como principal foco salientar a importância de perceber a cultura dentro de uma organização e a função estratégica da gestão de pessoas no processo de comunicação interna. Em um mundo organizacional onde a globalização, mudanças e fusões acontecem naturalmente do publico interno para que não haja uma reação negativa e certas mudanças.

\section{Considerando}

que, independentemente do nível hierárquico ocupado na organização, todos os funcionários, são comunicadores a interagir dentro do processo, mesmo através da comunicação informal, facilitará a integração e a participação de todos os envolvidos na empresa. A utilização dos diversos canais da comunicação pode tornar este processo mais eficiente e as barreiras superadas, permitindo a intervenção dos funcionários na apresentação de sugestões para melhoria da comunicação.

Para que a empresa alcance qualquer objetivo é fundamental que seus colaboradores compartilhem da mesma visão e da mesma missão. Assim a estratégia da comunicação interna deve ter como meta alinhar os discursos e a interpretação do publico interno, traduzindo essas mensagens, ressaltando o que é relevante para organização e por que e como pretendemos chegar lá. O objetivo desse trabalho foi analisar a cultura organizacional e como ela interfere na comunicação interna, ao fazer essa análise foi possível verificar o quanto é importante um bom plano de comunicação interna para dá mais confiança e estabilidade aos colaboradores, sendo assim uma ferramenta valiosa para motivar empregados e alcançar maior produtividade. Mas para que isso aconteça teria de implantar novas tecnologias partindo com um voto de confiança do fundador, para acabar com os antigos paradgmas e formar uma nova cultura dentro da empresa.

O empresário moderno deve acompanhar essas mudanças, agarrar as 
oportunidades, não se esquecendo de gerenciar bem a comunicação de uma empresa, é também monitorar e cativar seu publico interno, ou seja, os seus colaboradores. Se os colaboradores não dominam o que diz respeito à empresa em que trabalham, todos os esforços e investimentos terão sido em vão, afinal a missão primordial da comunicação interna é contribuir para o desenvolvimento e a manutenção de um clima favorável, propício ao cumprimento das metas estratégicas.

Uma das contribuições para o tema foi mostrar que é necessária uma cultura mais participativa de maior investimento com novas normas de comportamento e que se adéqua aos novos procedimentos e novas atividades. É importante destacar que a cultura organizacional não é algo que se possa descrever detalhadamente, mas é percebido por um profissional que entra na empresa, ou por um cliente que visita. Toda atividade da empresa precisa de um investimento, que por mais que isso venha gerar gastos financeiro, ou qualquer outro tipo de condição, o seu retorno será muito maior, com melhor qualidade nos serviços prestados, melhor satisfação da equipe, melhor clima organizacional, otimização de processos, mas segurança, agilidade no trabalho e são muitas as vantagens que conseguirá atingir a empresa, que o foco da organização é as pessoas e não a área ou departamento. Por isso ela tem que ser bem condicionada porque sempre vai existir um reflexo.

Se a cultura da empresa é ser inovadora, que está sempre buscando mudar para melhor, sempre criando, oferecendo novidades aos clientes, dando oportunidade aos seus profissionais, entre outros, o projeto de comunicação poderá ser desenvolvido mais rapidamente, pois será entendido e aceito mais facilmente.

A despeito das limitações da pesquisa, a primeira delas está relacionada ao tamanho da amostra por se tratar de um caso único, não possibilitando a comparação com outras empresas a fim de identificar as semelhanças e diferenças existentes, o esforço da investigação permitiu identificar que há necessidade de implantar métodos de comunicação interna utilizados em uma empresa do ramo da construção civil, abrindo espaço para futuras pesquisas.

Concluindo que a cultura na organização deve ser priorizada, os tabus devem ser derrubados, velhos paradigmas serão desprezados para a construção de um novo modelo de comunicação, onde todos os funcionários serão envolvidos e participantes. Procurando saber o que os funcionários pensam, serão a eles atribuído responsabilidades pelo sucesso da implantação de estratégias que visem à melhoria dos negócios. Assim encarada, a comunicação interna torna-se sem dúvida, um instrumento estratégico para benefícios 
na empresa e conseqüentemente, o sucesso da organização.

\section{Referências}

CAMPOLINA, H. Jr. Comunicação nas

Empresa. São Paulo: McGraw-Hill, 2001.

CHIAVENATO, I. Gerenciando com as Pessoas: Transformando o Executivo em um Excelente Gestor de Pessoas. Rio de Janeiro, RJ: Elsevier, 2005.

DIETRICH, P. et. al. The, Dynamics of Collaboration in Multipartner Project. Project Management Journal, v.41, n.4, p. 59-78, Sept.2010.

EASTERBY-SMITH, M. et al. Aprendizagem Organizacional e Organização de Aprendizagem. São Paulo: Atlas, 1999.

FLEURY, M. T. L; FLEURY, A. Construindo o Conceito de Competência. RAC, edição especial 2001, p.p. 183-196.

FLEURY, M. T. L; FISCHER, R. M. Cultura e Poder nas Organizações. Rio de Janeiro: Atlas, 1991.

FIGUEREDO, M. S. Comunicação Organizacional: Quando a Comunicação

Falha. TCC - (Especialização em Administração da Produção) ICPG Instituto Catarinense de PósGraduação. Santa Catarina Associação Educacional Leonardo da Vinci -. 2001.

FLICK, W. Introdução à Pesquisa Qualitativa. Tradução Joice Elias Costa. 3. Ed. Porto Alegre: Artmed, 2009.

FLORES, J. F. Análisis de Dados Cualitativos - Aplicaciones a la Investigación Educativa. Barcelona: PPU, 1994
GODOY, A. S. Estudo de Caso

Qualitativo. In: Silva, A. B., Godoy, C. K, 2006.

LAKATOS, E. M. Fundamentos de Metodologia Científica. 4. ed. São Paulo: Atlas, 2001.

MANZINI, E.J. Considerações sobre a Elaboração de Roteiro para Entrevista Semi-Estruturada. In: MARQUEZINE: M. C.; ALMEIDA, M. A.; OMOTE; S. (Orgs.) Colóquios sobre pesquisa em Educação Especial. Londrina:eduel, 2003. p.11-25.

MARCORI, M. Faces da Cultura e da Comunicação. São Caetano do Sul/SP. Difusão 2006.

MATTOS, P. L. C. L. Análise de Entrevistas não Estruturadas: da Formalização à Pragmática da Linguagem. In: SILVA, A. B.; GODOI, C. K; BANDEIRA-DE-MELO, R. (orgs). Pesquisa Qualitativa em Estudos Organizacionais: Paradigmas, Estratégias e Métodos. 2. ed. São Paulo, 2010, p. 347374.

MERRIAM, S. B. Qualitative Research and Case Study Applications in Education. 2. ed. San Francisco: Jossey Bass, 1998.

NORDVANG, A. D.; ROLLAND, D.; SIMPSON, K.; Organizational Change Management through Effective Internal Communication. International Journal of Information Systems and Change Management. V.3, $\mathrm{N}^{\circ} 3$, PP. 220-245, 2008

OLIVEIRA, D. de; CARVALHO, R. J.; ROSA, A. C. M. Clima Organizacional: Fator de Satisfação no Trabalho e Resultados Eficazes na Organização. Simpósio de Excelência em Gestão e Tecnologia. Tema: Gestão, Inovação e Tecnologia para a Sustentabilidade. , IX SEGeT 2012. 
PETTIGREW, Andrew M. (1989) - A

Cultura das Organizações é

Administrável? in Fleury, Maria T.L..

Cultura e Poder nas Organizações.

S.Paulo: Atlas, pp 145-146.

PIMENTA, M. A. Comunicação empresarial: Conceitos e Técnicas para Administradores. 7. ed. Campinas, SP: Alínea, 2010.

QUIVY, R; CAMPENHOUDT, L. V. Manual de Investigação em Ciências Sociais. 2. Ed. Lisboa: Gradiva, 1998.

REINALDO, P. Desafios para Implantação de um Plano de Comunicação Interna em um Órgão Public Federal. 2009. 150f. Dissertação (Mestrado em Sistema de Gestão)

Universidade Federal Fluminense. Niterói

RYNES, S., GEPHART, R. P., JR. From the Editors: Qualitative Research and the Academy of Management Journal. Academy of Management Journal, 47

(4), 454-461. 2004.

RUCK, K. WELCH, M. Valuing Internal Communication; Management and Employee Perspectives. Public Relations Review. V.38, n² 2, PP. 294-302, 2012.

SANTOS, J. P. Comunicação na Gestão Escolar. Revista Interdisciplinar Aplicada Blumenau, v.5, n.4, p. 01-22, TRI IV, 2011
SCHEIN, Edgar. H. Coming to a New Awereness of Organizational Culture. Sloan Management Review. Vol. 25, $\mathrm{n}^{\circ}$ 2. 1984

SCHEIN, E. Organization Cultures and Leadership: a Dynamic view. San Francisco: Jossey- Bass, P.1-26; 70-96 1985

THÉVENET, Maurice. Cultura de Empresa - Auditoria e Mudança, Lisboa: Monitor. 1989

TULL, D. S. \& HAWKINS, D. I. Marketing Research, Meaning, Measurement and Method. Macmillan Publishing Co. Inc., London, 1976.

YIN, R.K. Estudo de caso: Planejamento e Métodos. 3. Ed. Porto Alegre: Bookman, 2005.

VARGAS, D. L. S. ARBOLEDA, M. V. OBANDO, D. M. A. Nuevas Tecnologías em La Comunicación Interna en Empresas del Valle Aburrá. Revista Lasallita de Investigación. Vol.6 no.1. Caldas. Jan. /June 2009.

WELCH, M; Appropriateness and Acceptability. Employee Perspective of Internal Communication. Public Relations Review. V. 38, n 2 pp. 246254. 2012 